\title{
Stomach Pain, CTCAE 5.0
}

National Cancer Institute

\section{Source}

National Cancer Institute. Stomach Pain, CT CAE 5.0. NCI Thesaurus. Code C146774.

A disorder characterized by a sensation of marked discomfort in the stomach. 